\title{
Ultrasound imaging of undisplaced partial forearm fractures in children
}

\author{
Hazim K. Al-Allaf*, Faiza A. Al-Dubouni** \\ * College of Medicine, University of Mosul;** Al-Khansa'a Hospital.
}

(Ann. Coll. Med. Mosul 2008; 34(1): 9-15).

Received:4 ${ }^{\text {th }}$ Jun 2007; Accepted: $23^{\text {rd }}$ Jan 2008.

\section{ABSTRACT:}

Objective: To check the value of ultrasonography in the diagnosis of undisplaced partial forearm fractures in children.

Methods: A case series study was conducted in AL-Khansa'a and Al-Zahrawy teaching hospitals in Mosul over a period between November 2005 to October 2006. One hundred patients (54 male and 46 female) between the age of 2-15 years suffering from high clinical suspicion of non displaced forearm fractures were first examined by ultrasound (Sonoline SL 100, Siemens Nurnberg Germany) with $7.5 \mathrm{MHZ}$ linear array transducer by a radiologist who gave an immediate report. Standard two views radiography of the forearm then obtained. The radiographs were reported by another senior radiologist. Ultrasonographic and radiographic reports were then compared.

Results: One hundred patients were examined, 54 male and 46 female with male/female ratio 1:1.7. The type of fractures found were 46 torus type, 48 greenstick and 6 were plastic deformity. Subperiosteal haematoma was encountered in $100 \%$ of the fractures, bending sign was $100 \%$ and finally reverberation echoes was shown in all the fracture types too.

Conclusion: Ultrasound is a useful method in the diagnosis of undisplaced forearm fractures in children. It is an easy, safe, fast and in-expensive procedure. More studies are indicated to confirm its reliability in different pediatric fractures.

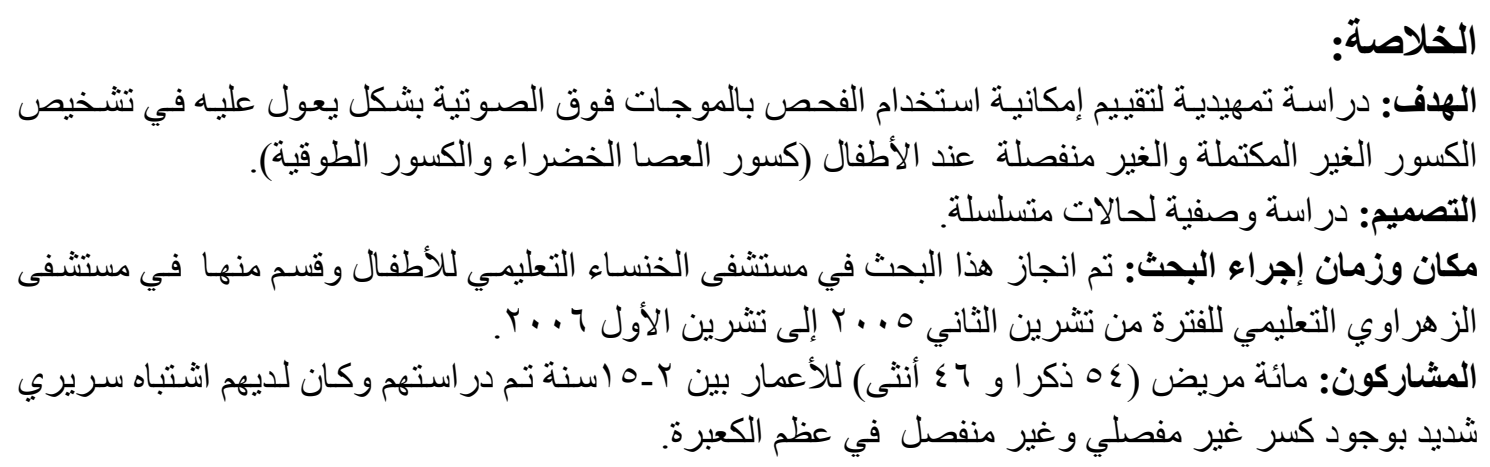


طريقة البحث: جميع المرضى تم فحصهم بواسطة الموجات فوق الصوتية أو لا (باستخدام جهاز سيمنس ألماني

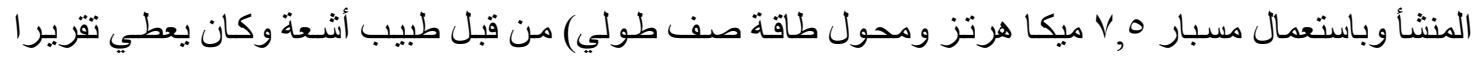

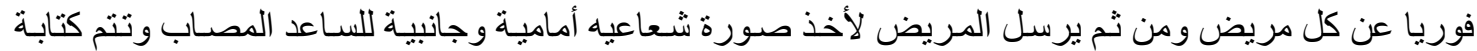
تقارير الأشعة من قبل طبيب أثنعة اختصاصي آخر ثم يتم مقارنة تقارير الموجات الفوق صوتية مع تقارير الأشعة المانة وتثبيت الحالة النهائية.

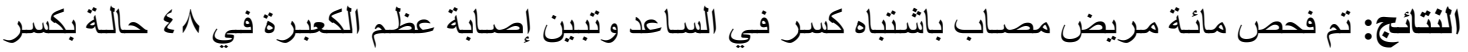

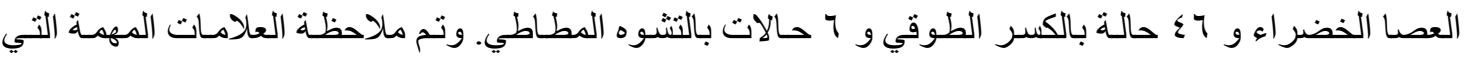

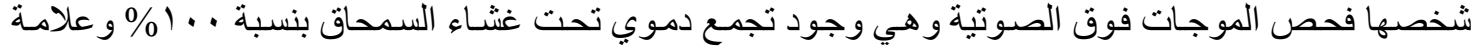

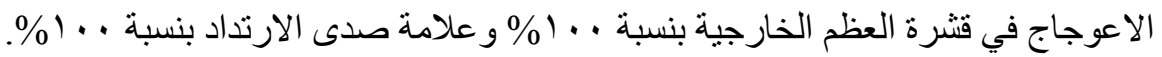

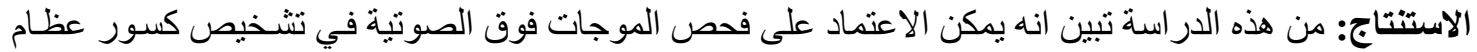

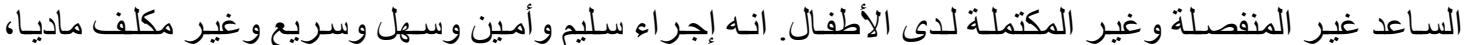
وينصح بإجر اء در اسات مستقبلية لتحديد إمكانية وقدرة هذا الفحص في تشخيص الكسور المختلفة لدى الأطفال

$\mathbf{T}$ he hospital assessment of children with injuries present a particular problem. They are often in pain, scared and intimidated by their surroundings. Anxious parents often compound the fears of their children. ${ }^{(1)}$

Evaluation of an extremity trauma with clinical and roentgenographic examination is mandatory for the diagnosis of fractures. However, ionized radiation can be hazardous to the epiphyses in paediatric patients. ${ }^{(2)}$ Although exposure to high dose ionizing radiation is known to be carcinogenic and teratogenic, the harmful effects of low dose ionizing radiation are debated. ${ }^{(3)}$ However it is widely held view that the effect of exposure are cumulative and may contribute to the development of significant problems over a lifetime, especially in children.

The ability to diagnose fractures by ultrasonography in ossified and unossified region of the bones has been reported in the literature. $^{(4)}$ In some of these studies, ultrasound was found to be even more sensitive than radiography for detection of fractures in such regions as sternum and forearm.

Diagnostic ultrasonography has been well researched in bony imaging. The large difference in acoustic impedance at the junction of soft tissue and bone causes almost total reflection of sound energy providing a strong image of bone surface. Any imperfection (for example, steps, breaks etc), should therefore be easily visible. This technique is particularly applicable in children given their comparatively small soft tissue thickness and its non-invasive nature. ${ }^{(5)}$

The studies of fracture by ultrasound examination was tried by many people ${ }^{(6-8)}$. Many other studies proved that high resolution sonography were reliable and accurate methods of evaluating occult fractures of scaphoid waist and undisplaced pediatric fractures ${ }^{(9-11)}$.

Ultrasound has been receiving considerable attention in assessment of fractures due to its ease of use and lack of radiation. Interruption of cortical bone, 
paraosseous haematomas, bending signs and reverberating echoes have been defined as ultrasound finding in fractures ${ }^{(2-}$ 10)

The ultrasound findings in paediatric fractures are many and the most important ones of these are, the subperiosteal haematoma, bending of the cortex, cortical disruption and reverberation echoes ${ }^{(12-17)}$.

Fractures of bone occur when there is break in the continuity of its contour. It may be either complete or incomplete fractures. Incomplete occur mostly in children where the bone resilience is the greatest, and are of three types, plastic fracture, torus fracture, green stick fracture.

The aim of this study is to assess the value of ultrasound in the diagnosis of undisplaced partial forearm fractures in children and to analyse the ultrasound findings in different type of paediatric fractures.

\section{Patients and methods:}

From November 2005 to October 2006, one hundred child aged 2-15 years, with suspected forearm fracture were examined. They were referred to the orthopedic consultation clinic at ALKhansa'a and Al-Jamhory teaching hospitals in Mosul. The clinical findings were recorded, which included mainly swelling, and tenderness at the site of trauma on the forearm. Ultrasonographic examination at the site of the trauma was performed with (Sonoline SL 100), Siemens Nurnberg Germany) equipment using 7.5 linear high frequency transducers. The region with maximal tenderness in the forearm was evaluated by sagittal, longitudinal and transverse planes, both in supination and pronation. Uninjured contralateral bone was examined for comparison.

After completing the ultrasound examination, the patients were examined by radiography taking two standard views for the bones (anteroposterior and lateral views). The result was recorded by another senior radiologist. The sonographic results were analysed and then compared to the radiographic findings. Some of the patients were advised to be rechecked by radiography 1-2 weeks later for follow up and to be compared with the sonographic results obtained.

\section{Results:}

One hundred patients were included in this study. They were 54 male and 46 female children with a ratio 1:1.7. Their ages were 2-15 years with mean age of (8.5). All these patients had fractures in their forearm particularly the radius which were detected by sonography and all confirmed by radiography. The number of patients in relation to the age and sex is shown in Figure (1). The sonographic findings associated with different types of fractures varied from subperiosteal haematoma, bending of the cortex, interruption of the cortex and reverberation echoes are shown in Table (1). While the 
patients' age and sex distribution in relation to their forearm fractures are shown in Table (2).

Subperiosteal haematoma and reverberating echoes. Figure $(2,3)$ are seen in all types of fractures in our study, while bending of the cortex Figure (4) is seen in all patients with greenstick

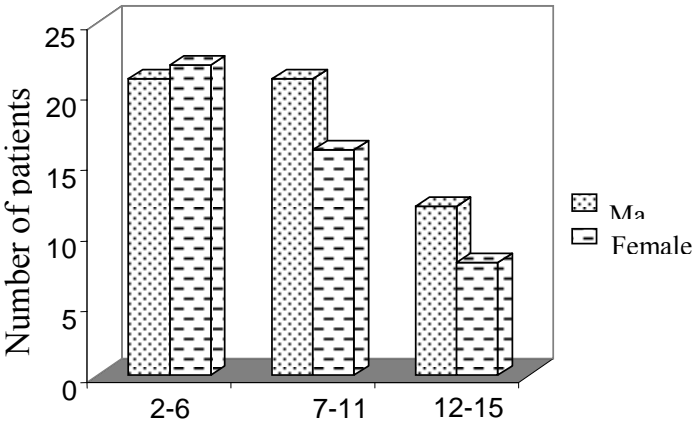

Age in years

Fig. (1): Histogram showing the number of cases in relation to the age \& sex.

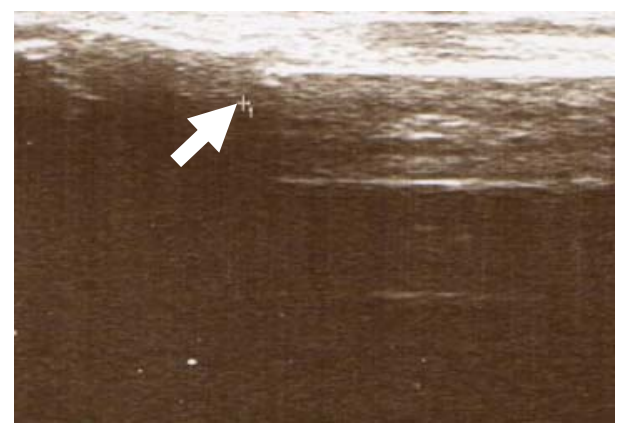

Fig (3): Showing reverberation echoes (arrow) in a patient with fractured radius. fractures and plastic deformity, but it is seen in $45.6 \%$ of patients with torus fracture. Interruption of the cortex (Figure 5 ) is seen in all patients with torus fracture but it is only seen in $35.5 \%$ of patients with greenstick fracture and is not seen with plastic deformity.

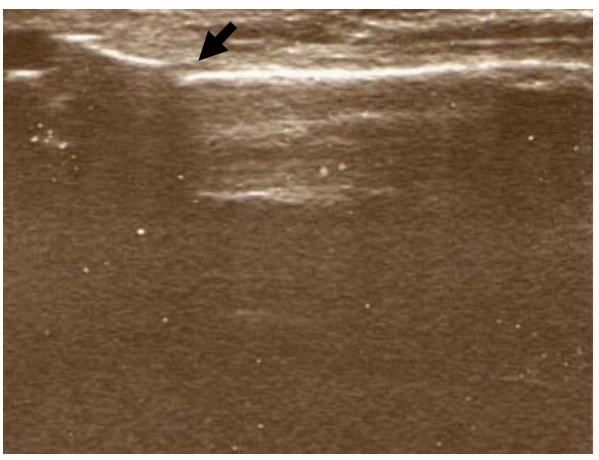

Fig. (2): Showing subperiosteal haematoma ( arrow ) in a child with a greenstick fracture of the radius.

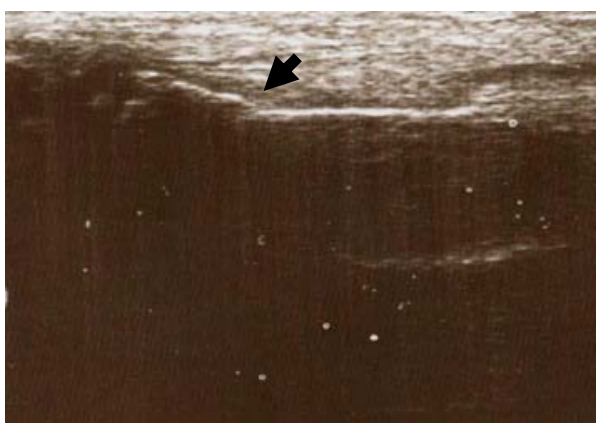

Fig (4): Showing bending of the cortex (arrow) in a child with a greenstick fracture of the radius.

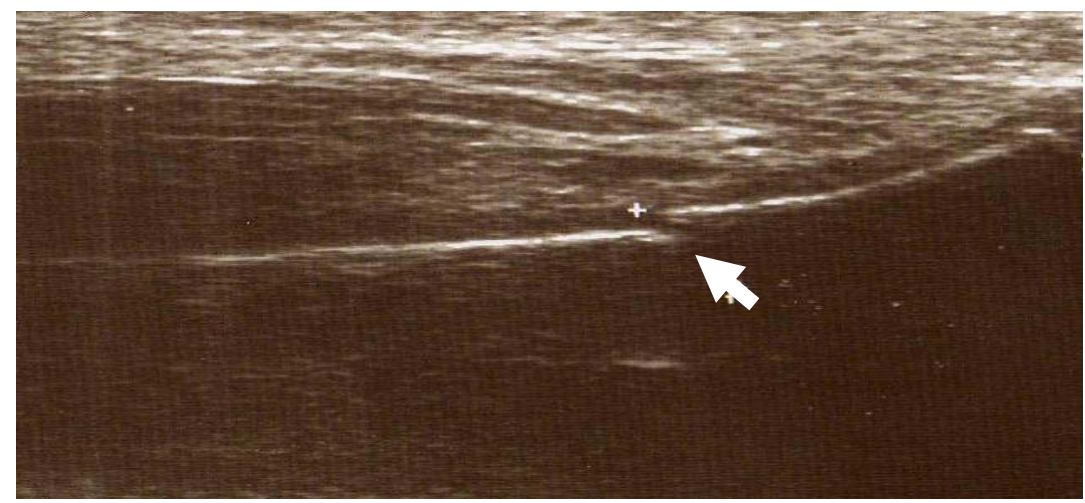

Fig (5): Interruption of the cortex $(+)$ is seen clearly in a patient with fractured radius . reverberation echoes are also noticed (arrow). 
Table (1): Shows the sonographic finding in relation to the type of fractures.

\begin{tabular}{|c|c|c|c|c|}
\hline & Torus & Greenstick fracture & Plastic deformity & Total \\
\hline No. of cases & 46 & 48 & 6 & 100 \\
\hline Subperiosteal & 46 & 48 & 6 & 100 \\
hematoma & $100 \%$ & $100 \%$ & $100 \%$ & $100 \%$ \\
\hline Bending & 22 & 48 & 6 & 76 \\
& $45.6 \%$ & $100 \%$ & $100 \%$ & $76 \%$ \\
\hline Interruption of the & 46 & 17 & 0 & 63 \\
cortex & $100 \%$ & $35.5 \%$ & $6.0 \%$ & $63 \%$ \\
\hline Reverberation & 46 & 48 & $100 \%$ & 100 \\
echoes & $100 \%$ & $100 \%$ & $60 \%$ \\
\hline
\end{tabular}

Table (2): shows the sex and age of patients in relation to type of fractures.

\begin{tabular}{|c|c|c|c|c|c|}
\hline \multirow{4}{*}{ Male } & $\begin{array}{c}\text { Age of } \\
\text { patient }\end{array}$ & Torus fracture & $\begin{array}{c}\text { Greenstick } \\
\text { fracture }\end{array}$ & $\begin{array}{c}\text { Plastic } \\
\text { deformity }\end{array}$ & Total \\
\hline \multirow{4}{*}{ Female } & $2-6$ & 6 & 14 & 0 & 20 \\
\cline { 2 - 7 } & $7-11$ & 22 & 4 & 0 & 26 \\
\cline { 2 - 7 } & $12-15$ & 2 & 4 & 2 & 8 \\
\cline { 2 - 7 } & $12-15$ & 2 & 16 & 0 & 18 \\
\hline \multirow{2}{*}{ Total } & $7-11$ & 4 & 6 & 2 & 12 \\
\hline
\end{tabular}

\section{Discussion:}

Fractures of the forearm and especially the radius are one of the commonest injuries in children. If these fractures are uncomplicated and undisplaced and properly treated then they will heal with no deformity. With the increased awareness over the danger of irradiation even with small doses, alternative to radiography was sought. The use of ultrasound in all aspect of diagnostic medicine is rising. So it is used to diagnose fracture in children, in order to decrease the risk of irradiation on the epiphyseal growth of bones. ${ }^{(17)}$ Sonographic evaluation of fractures in paediatric age group, is a quick procedure that takes few minutes, economic, and can be available as bed-side sonography in emergency department, without the need to shift the patient to radiology department ${ }^{(19)}$.

Previous trial to diagnose fractures by ultrasound used therapeutic ultrasound equipment with $1-2 \mathrm{MHZ}$ transducers rather than high resolution sonography with $7 \mathrm{MHZ}$ transducer and more. It was proved that therapeutic sonography causes heating of the 
bone, pain and damage which are not present when high frequency ultrasound is used. ${ }^{(18)}$

A child's periosteum is thicker than adults, stronger, and more readily elevated from the metaphysis and diaphysis of the bone. For this reason the periosetum is usually injured to some extent in all fractures, and subperiosteal haematoma at the fracture site, is frequently and almost always seen. This haematoma can be clearly documented by sonography. ${ }^{(13)}$ In our study it was the most valuable findings, was seen in all paediatric fractures, and it was in agreement with William ${ }^{(10)}$ and Fatih ${ }^{(2)}$ studies.

Reverberation echoes which is due to reflection of ultrasound waves from the medullary bone instead of the cortical bone at the fracture site will act as a window for the ultrasound waves to pass through. This sign was present in all patients in our study, which is similar to William ${ }^{(10)}$ and Fatih ${ }^{(2)}$ studies where this sign was seen in $100 \%$ of all paediatric fractures.

Bending of the cortex was present in all incomplete fracture types (greenstick and plastic deformity). This can be due to presence of mirofractures. In our study any deformation of the cortex without gaping was easily demonstrated by ultrasound in incomplete fractures. This finding was in agreement to previous studies too ${ }^{(2,10)}$.

Interruption of the cortex or stepping is very easily detected once the ultrasound transducer is put on the site of maximal tenderness on the bone, and it represents the site of the fracture. This sign was seen in all cases of torus fracture in our study, similar to the result of Fatih ${ }^{(2)}$ study, but the cortical interruption was detected in $35.5 \%$ of greenstick fracture in this study compared to $50 \%$ in the study done by Fatih..$^{(2)}$

\section{Conclusion:}

Ultrasound is an easy and useful diagnostic tool for evaluation of paediatric fractures. We hope that ultrasound will be used routinely for diagnosis of paediatric fractures in the future. Further studies are indicated to confirm its reliability in different paediatric fractures.

\section{References:}

1- Dominic W, Roland W, and Mark C. Ultrasound imaging of forearm fractures in children. J Accid Emerg. Med. 2000; 17: 22-24.

2- Fatih E, Deniz A, M. Murad Ulsu, Eftal G. Ultrasonographic findings in paediatric fractures. The Turkish Journal of paediatrics 2003; 45: 136-140.

3- Grazer RE, Meislin HW, Westerman BR. A nine years evaluation of emergency department personnel exposure to ionizing radiation. Ann Emerg Med. 1987; 16: 3402 [Medline].

4- Hubner U, Schlichtw, Outzen S, Barthel $M$, Halsband $H$. Ultrasound in the diagnosis of fracture in children. J. Bone Joint Surg. 2000; 82: 1170-1173.

5- Moss A, Mowat AG. Ultrasound assessment of stress fracture. BMJ 1993;1286:1949 [Medline].

6- Schenouauda NA. England JP. Ultrasound diagnosis of scaphoid fracture J. Hand Surgery 1987; 12(1): 43-45.

7- Graif M, Stabl-kent V, Ben-Ami T. Sonographic detection of occult bone fracture paediatric radiol 1988; 18: 383385. 
8- Katz-R, Landman J, Dultizky F, Bar-ziv. Fracture of the clavicle in new born. Journal of ultrasound in medicine; 1988; 7 : 21-3.

9- Grechenig W, Clement HG, Fellinger M. Scope and limitation of ultrasonography in the documentation of fractures. An experimental study. Arch Ortho trauma Surg. 1998; 117: 368-371.

10- William D. Ultrasound imaging of forearm fractures in children. Available alternative. J 17 Accid. Emergency Med. 2000; 17: 22-24.

11- Oliver H, Bonneyfoy O, Moivard M. Occult fractures of the waist of the scaphoid. AJR 2002; 178: 1239-1245.

12- Rathfelder FJ, Paar O. Possibilities for using sonography as a diagnostic procedure in fracture during the growth period. Unfall 19chirurg 1995; 98: 645-649.

13- Blab E, Geibler W, Rokitansky A. Sonographic management of infantile clavicular fracture. Paediatric Surg. 1999; 15: $251-254$
14- Ogden JA, Gany TM. The biological aspects of children fracture, $4^{\text {th }}$ ed. Philadelphia. Lippencott 1996; 19-52.

15- May DA, Disler DG, Jone EA. Using sonography to diagnose an unossified medial epicondyle avulsion in a child. AJR 2000; 174: 115-117.

16- Dithefield A, Sampson MA, Taylor GA. Ultrasound diagnosis of sleeve fracture of patella. Clinical Radiol 2000; 55: 721-722.

17- Kayser Ralph. Ultrasonographic imaging of fractures of the clavicle in newborn infant. J. bone and joint surgery 2003;162: 44.

18- Decruz Dj, Taylor RH, Savage B. Ultrasound assessment of suspected scaphoid fracture. Arch. Emerg. Med. 1998; 5: 97-100 [Medline].

19- Christian F, Matthew S, Alexander Z and Graig A. Bedside ultrasound appliance. Acad. Emerg. Med. 2005;(12):5,76. 